\title{
Infection par le SRAS-CoV-2 associée à un pneumothorax spontané
}

\author{
Sagar Rohailla MD MSc, Najma Ahmed MD, Kevin Gough MD
}

- Citation : CMAJ 2020 May 11;192:E510. doi : 10.1503/cmaj.200609-f; diffusion hâtive le 21 avril 2020

Voir la version anglaise de l'article ici : www.cmaj.ca/lookup/doi/10.1503/cmaj.200609

$\mathbf{U}$

n homme de 26 ans s'est présenté au service des urgences pour une douleur pleurétique du côté droit du thorax apparue soudainement 3 jours auparavant et un essoufflement progressif. Le patient n'avait pas voyagé dans les 2 semaines précédentes, n'avait aucun antécédent de traumatisme thoracique et n'avait pas eu de fièvre, de toux ou d'autres symptômes systémiques. Avant l'apparition des symptômes, il était en bonne santé et ne prenait aucun médicament. La personne qui réside avec lui avait eu une toux sèche pendant 1 semaine. Le patient a préféré ne pas donner plus de renseignements.

À l'examen de ses signes vitaux, le patient avait une température et une pression artérielle $(118 / 80 \mathrm{~mm} \mathrm{Hg})$ normales ainsi qu'un rythme cardiaque de 122 battements par minute. Il présentait une légère détresse respiratoire avec une saturation normale à l'air ambiant. Son indice de masse corporelle était de $17,6 \mathrm{~kg} / \mathrm{m}^{2}$. Les résultats des analyses sanguines indiquaient une lymphopénie $\left(0,69 \times 10^{9} / \mathrm{L}\right.$ [normale : 1,0 à $3,2 \times 10^{9} / \mathrm{L}$ ]). Une radiographie pulmonaire a révélé un pneumothorax important avec collapsus pulmonaire complet du côté droit sans déviation médiastinale (figure $1 \mathrm{~A}$ ).

En raison des symptômes respiratoires du patient, nous avons réalisé un écouvillonnage du nasopharynx, qui a permis de confirmer une infection par le coronavirus du syndrome respiratoire aigu sévère 2 (SRAS-CoV-2) par PCR quantitative après transcription inverse en temps réel ${ }^{1}$. Nous avons procédé au drainage thoracique à l'aide d'un petit cathéter, qui a ensuite été retiré, et le médecin a pris toutes les précautions en matière d'équipement de protection individuelle, y compris l'utilisation d'un masque de protection respiratoire N95. Après 48 heures, le pneumothorax et les symptômes du patient se sont résorbés (figure 1B). Le patient a reçu son congé de l'hôpital alors que son état était stable, et il a signalé la résolution complète des symptômes par vidéoconférence le jour suivant le congé.

Les symptômes du patient n'ont pas suivi la trajectoire attendue de la maladie à coronavirus 2019 (COVID-19); il y avait toutefois une lymphopénie, qui a été bien décrite chez les personnes atteintes de cette maladie ${ }^{2}$. Le pneumothorax spontané est le plus courant chez les hommes jeunes, grands et minces, et on sait qu'il peut s'agir d'une complication des maladies infectieuses des poumons ${ }^{3}$. Une association entre la COVID-19 et un pneumothorax spontané a déjà été décrite, mais son incidence sur le pronostic est inconnue ${ }^{4}$.

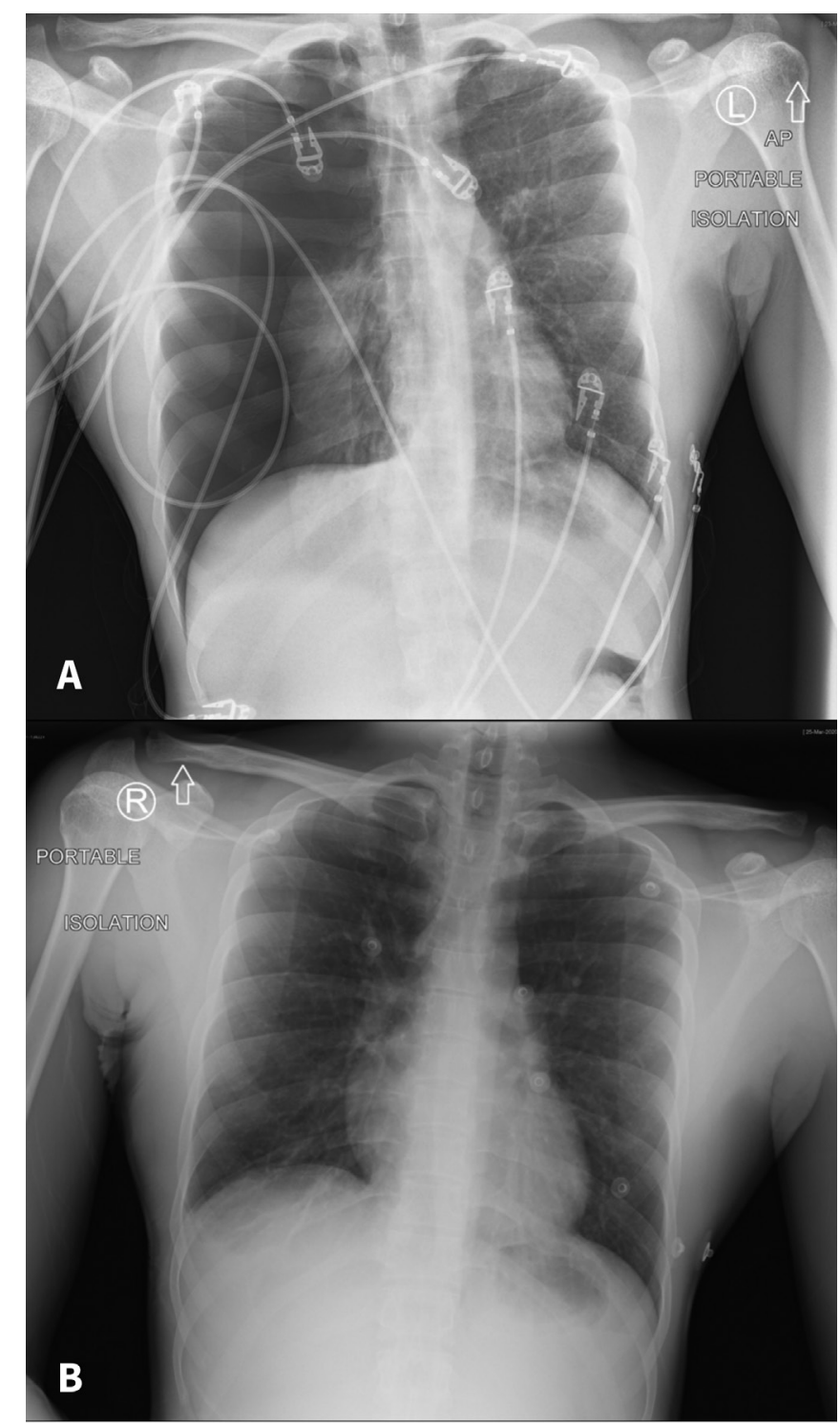

Figure 1 : Radiographie pulmonaire d'un homme de 26 ans présentant une infection par le coronavirus du syndrome respiratoire aigu sévère 2 montrant (A) un pneumothorax important et un collapsus pulmonaire complet du côté droit lors de l'admission à l'hôpital. Le poumon gauche semble normal. (B) Le poumon en expansion après le retrait du drain thoracique. Un épanchement pleural est visible du côté droit, avec une atélectasie mineure. Il y a absence d'œdème pulmonaire ou de consolidation. 


\section{Références}

1. Corman VM, Landt O, Kaiser M, et al. Detection of 2019 novel coronavirus (2019-nCoV) by real-time RT-PCR. Euro Surveill 2020;25. doi: 10.2807/1560-7917 .ES.2020.25.3.2000045.

2. Huang C, Wang Y, Li X, et al. Clinical features of patients infected with 2019 novel coronavirus in Wuhan, China. Lancet 2020;395:497-506.

3. Sahn SA, Heffner JE. Spontaneous pneumothorax. N Engl J Med 2000;342:868-74.

4. Salehi S, Abedi A, Balakrishnan S, et al. Coronavirus disease 2019 (COVID-19): a systematic review of imaging findings in 919 patients. AJR Am J Roentgenol 2020 Mar. 14 [Cyberpublication avant impression];1-7. doi: 10.2214/AJR .20 .23034 .

Intérêts concurrents : Aucun déclaré.

Cet article a été révisé par des pairs.

Les auteurs ont obtenu le consentement du patient.

Affiliation : Hôpital St. Michael, Université de Toronto, Toronto, Ont.

Correspondance : Kevin Gough, Kevin.Gough@unityhealth.to 